\title{
INFLUENCE OF EXPIRATORY FLOW IN THE EXHALED NITRIC OXIDE TEST
}

\author{
Toshio Ogoshi, Yukiko Miyazaki, Madoka Ishibashi \\ and Tomoaki Kai
}

Second Department of Otolaryngology, Toho University School of Medicine, Tokyo

We determined whether expiratory flow influences the level of exhaled nitric oxide (NO) in a test using a bagtrap.

Subjects were 14 healthy volunteers whose exhaled NO was measured through the mouth and nose at 4 different expiratory flow rates. Oral and nasal exhaled NO were measured with subjects inhaling NOfree air using a bagtrap based on a chemiluminescence NO analyzer, ML9841, at a detection limit of 1 part per billion (ppb). The 4 expiratory flow rates were identified at $0.05,0.1,0.2$, and $0.3 \mathrm{~L} / \mathrm{s}$.

Oral exhaled NO concentrations were 36.7 (SE: \pm 7.30$) \mathrm{ppb}$ at an expiratory flow of $0.05 \mathrm{~L} / \mathrm{s}, 26.7$ $( \pm 5.45)$ at $0.1,20.18( \pm 4.25)$ at 0.2 , and $16.4( \pm 3.85)$ at 0.3 . Oral exhaled NO concentrations inversely correlated with the expiratory flow rate $(\mathrm{R}=0.941)$. Nasal exhaled NO concentrations were $72.6( \pm 8.39)$ at $0.05 \mathrm{~L} / \mathrm{s}, 59.9( \pm 8.31)$ at $0.1,39.0( \pm 4.49)$ at 0.2 , and $29.1( \pm 4.09)$ at 0.3 . Nasal exhaled NO concentrations had also inversely correlated with the expiratory flow rate $(R=0.983)$. Nasal exhaled NO concentrations were significantly higher than oral at all flow rates.

We concluded that oral and nasal exhaled NO concentrations using a bagtrap were flow-dependent, and thus constant expiration $(0.1 \mathrm{~L} / \mathrm{s})$ is recommended.

Key words : oral exhaled nitric oxide, nasal exhaled nitric oxide, expiratory flow rate, bagtrap method

\section{Introduction}

Measurement of nitric oxide (NO) concentration in exhaled air haș recently been proposed as a non-invasive means of assessing the degree of lower and upper airway inflammation, including asthma ${ }^{1,2,3,4)}$.

Many investigators have measured exhaled NO using a chemiluminescence analyzer, but the reported values have varied widely, reflecting differences in technological and/or measurement technique. Therefore, there is a need to standardize the measurement if this approach is to be widely applied, and to allow comparison of results from different laboratories. Exhaled NO was measured using either the singlebreath method or bagtrap method. We previously found using the bagtrap method that a high level of inhaled ambient $\mathrm{NO}$ influenced exhaled $\mathrm{NO}^{5)}$. The purpose of this study was to determine using the bagtrap method whether expiratory flow influences the level of oral and nasal exhaled NO.

\section{Material and Methods}

\section{Subjects}

Fourteen healthy volunteers (three females and eleven males) with a mean age of 26 years (range 16 to 51 years) were enrolled in this study. None of the subjects had history of respiratory or cardiac disease and none were taking medication. All subjects had normal spirometric values and no restrictions were placed on the intake of food or liquids before the test. Three males were smokers, but they did not smoke 48 hours prior to the test. 


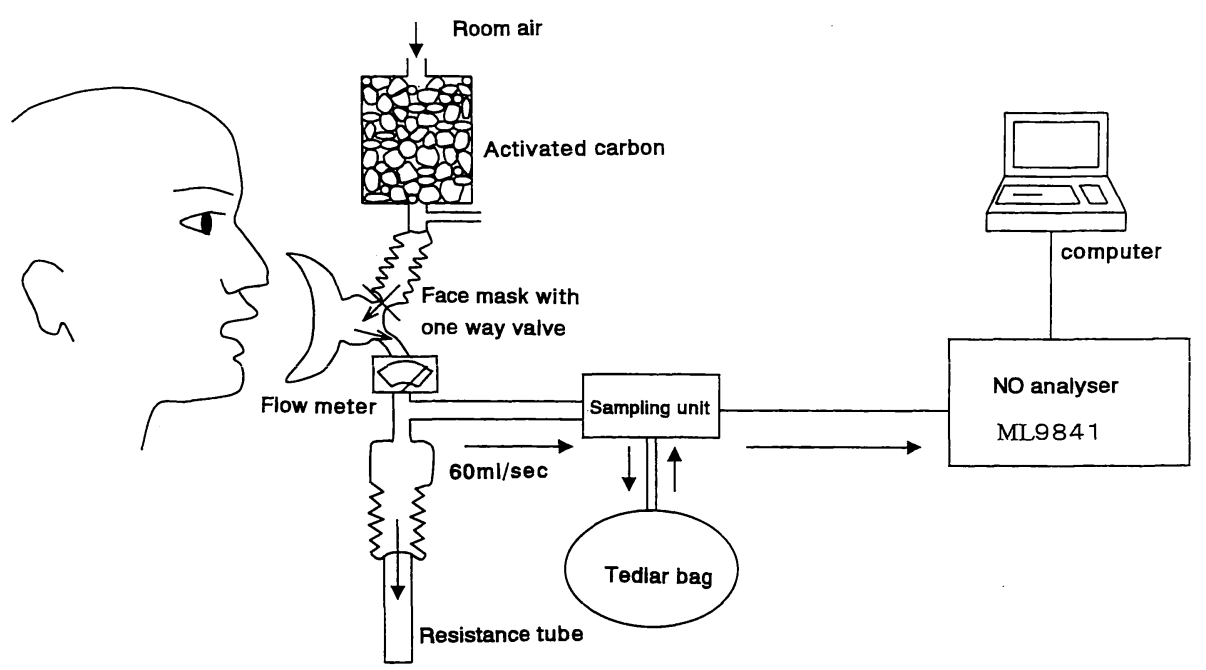

Fig. 1 Diagrammatic representation of the bag-trap system.

\section{Equipment (Fig.1)}

Oral and nasal exhaled NO was measured using the bag method connected to a chemiluminescece analyzer (ML9841, MONITOR LAB, USA) with a lower limit of detection of $1 \mathrm{ppb}$. Calibration to $437 \mathrm{ppb}$ was performed every day using a reference standard NO sample. Exhaled gas was sampled with a constant flow of $60 \mathrm{ml} / \mathrm{s}$ using side-stream system to the sampling bag (Tedlar bag), and immediately measured. The bag was tested for leaks of NO and nonreactivity to NO. The response time of the ML9841 was approximately $30 \mathrm{sec}$, and thus NO concentrations were recorded over $60 \mathrm{~s}$.

Expiratory flow rate was measured through a hot wire type flow meter (CHEST Co, Ltd.)

\section{Procedure}

The measurement circuit consisted of a face mask connected to a non-rebreathing one-way valve, through which the seated volunteer inhaled NO-free air (air filtered through activated carbon). NO concentration of inhaled air was measured before each measurement of exhaled NO test.

Measurements were taken while subjects breathed either through the mouth or nose. During oral breathing, subjects wore noseclips and breathed into a face mask. For nose breathing, the mouth was closed and subjects breathed into the face mask. In oral breathing, the back-pressure created by expiration against resistance $\left(10.3 \mathrm{~cm} \mathrm{H}_{2} \mathrm{O}\right)$ was used to the soft palate closed, which prevented the contamination of exhaled air with nasal NO. During expiration, subjects were instructed to maintain a constant flow. The exhaled air collected through the Teflon tube in the bag was analysed within $3 \mathrm{~min}$.

Two exhalations were measured at four different expiratory flow rates, $0.05 \mathrm{~L} / \mathrm{s}, 0.1 \mathrm{~L} / \mathrm{s}, 0.2 \mathrm{~L} / \mathrm{s}$, and $0.3 \mathrm{~L} / \mathrm{s}$. Average NO concentrations are recorded. Inspiration time was 5 seconds for every flow rate. Exhalation time was 10 seconds at flow rates of 0.05 , $0.1,0.2 \mathrm{~L} / \mathrm{s}$ and 5 seconds at $0.3 \mathrm{~L} / \mathrm{s}$. Sampling time was 25 seconds and sampling volume was $1500 \mathrm{ml}$ $(60 \mathrm{ml} \times 25 \mathrm{sec})$. All subjects started with the lowest flow rate and increased their rate with each successive set of two exhalations.

\section{Statistical analysis}

Student's t-test was used for statistical analysis. A value less than 0.05 was taken to indicate significance. All results are given as mean and standard error (SE).

\section{Results}

\section{Oral exhaled NO}

The mean (SE) NO concentration at the four expiratory flow rates was 36.7 (7.30) $\mathrm{ppb}$ at $0.05 \mathrm{~L} / \mathrm{s}, 26.7$ (5.45) $\mathrm{ppb}$ at $0.1 \mathrm{~L} / \mathrm{s}, 20.1(4.24) \mathrm{ppb}$ at $0.2 \mathrm{~L} / \mathrm{s}$, and 16.4 (3.85) $\mathrm{ppb}$ at $0.3 \mathrm{~L} / \mathrm{s}$. A strong inverse linear correlation was observed between oral exhaled NO concentration and expiratory flow rate $(\mathrm{R}=0.941)$. (Fig.2)

\section{Nasal exhaled NO}

The mean (SE) NO concentration at the four expir- 


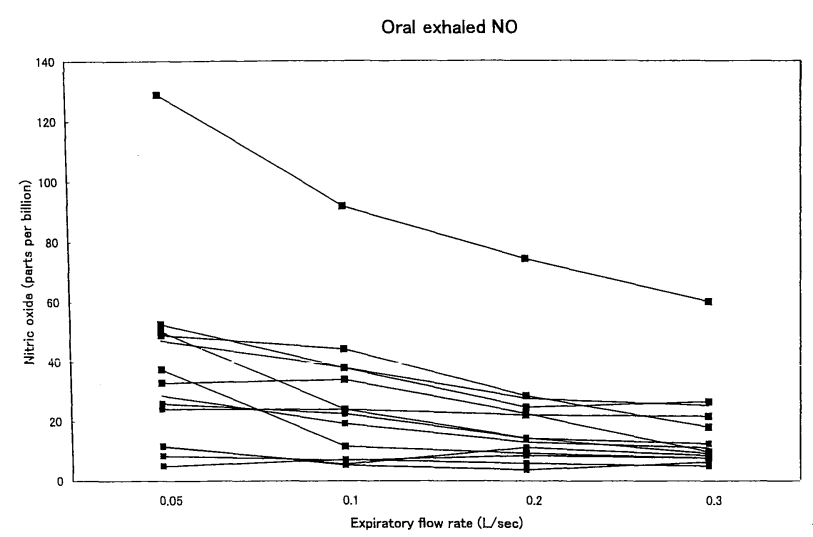

Fig. 2 Oral exhaled NO concentrations at different expiratory flow rates for 14 individuals. Each point is mean of two exhalations. Analysis of variance showed significant difference across flow rate, with a wide variationamong individual subjects. Flow rate 0.05 vs 0.1 was $\mathrm{p}<0.01,0.1$ vs 0.2 was $\mathrm{p}<0.005,0.2$ vs 0.3 was $\mathrm{p}<0.05$.

atory flow rates was $72.6(8.39) \mathrm{ppb}$ at $0.05 \mathrm{~L} / \mathrm{s}, 59.9$ (8. 31) $\mathrm{ppb}$ at $0.1 \mathrm{~L} / \mathrm{s}, 39.0(4.49) \mathrm{ppb}$ at $0.2 \mathrm{~L} / \mathrm{s}$ and $29.5(4$. $09) \mathrm{ppb}$ at $0.3 \mathrm{~L} / \mathrm{s}$. A strong inverse linear correlation was observed between nasal NO concentration and expiratory flow rate $(\mathrm{R}=0.983)$. (Fig.3)

Nasal exhaled NO concentrations were significantly higher than oral exhaled NO concentrations at all flow rates. (Table)

\section{Discussion}

Nitric oxide is producted in the respiratory tract within the nasal cavity and paranasal sinuses ${ }^{6,7)}$. Oral exhaled NO means the proportion of NO arising from the infra-palatal airway. Nasal exhaled NO means the NO arising from infra-palatal airway and nasal cavity. Nasal NO means the proportion of NO arising from nasal cavity. Oral exhaled NO, nasal exhaled NO and nasal NO are measured either single (or breath by breath) method ${ }^{8,9)}$ or bagtrap method. Some studies have observed that exhaled NO levels are influenced by changes in the measurement conditions and methods ${ }^{10,11,12)}$.

The single-breath method, includes a rapidresponse analyser, allows for fractioning of a breath into early and late phases. Hence, it is possible to measure peak NO (early phase) and NO plateaus

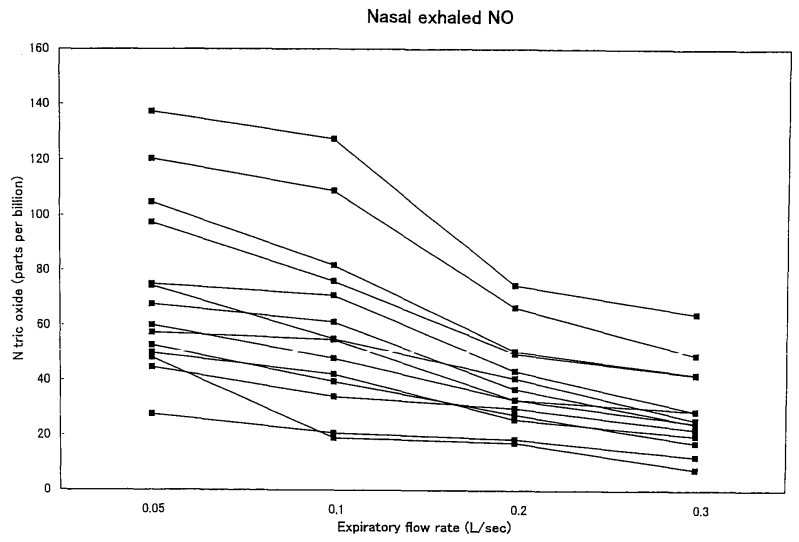

Fig. 3 Nasal exhaled NO concentrations at different expiratory flow rates for 14 individuals. Each point is mean of two exhalations. Analysis of variance showed significant difference across flow rate, with a wide variationamong individual subjects. Flow rate 0.05 vs 0.1 was $\mathrm{p}<0.0001,0.1$ vs 0.2 was $\mathrm{p}<0.0001,0.2$ vs 0.3 was $\mathrm{p}<0.001$

Table. Nitric oxide concentrations in oral and nasal exhaled air at four different expiratory flow rates (ppb: mean $\pm \mathrm{SE}$ )

\begin{tabular}{|l|l|l|l|l|}
\hline & $0.05 \mathrm{~L} / \mathrm{sec}$ & $0.1 \mathrm{~L} / \mathrm{sec}$ & $0.2 \mathrm{~L} / \mathrm{sec}$ & $0 / 3 \mathrm{~L} / \mathrm{sec}$ \\
\hline $\begin{array}{l}\text { Oral } \\
\text { Exhaled NO }\end{array}$ & $36.7 \pm 7.30$ & $26.7 \pm 5.45$ & $20.1 \pm 4.25$ & $16.4 \pm 3.85$ \\
\hline $\begin{array}{l}\text { Nasal } \\
\text { Exhaled NO }\end{array}$ & $72.6 \pm 8.39$ & $59.9 \pm 8.31$ & $39.0 \pm 4.49$ & $29.1 \pm 4.09$ \\
\hline$P$ & $<0.005$ & $<0.005$ & $<0.01$ & $<0.05$ \\
\hline
\end{tabular}

(late phase), as well as to measure exhaled NO using the bag (mean NO) and nasal NO. The bagtrap method has a slow-response but high detectability and reproducibility of exhaled NO and nasal NO. Our method had high acceptability by the both subjects and technicians. On the other hand, it does not distinguish NO produced during the early phase of exhalation from that produced during the late phase of exhalation. thus, it only measures the mean NO concentrations.

Nasal exhaled NO was diluted with air from the lower airway, and thus the direct nasal sampling method is used to distinguish NO produced by nasal and paranasal sinal origins. Kimberly et $\mathrm{al}^{13)}$, report- 
ed that NO release during mouth breathing using single-breath method was $68 \pm 6 \mathrm{nl} / \mathrm{min} / \mathrm{M} 2$, during nose breathing was $141 \pm 17 \mathrm{nl} / \mathrm{min} / \mathrm{M} 2$, direct nasal sampling NO was $217 \pm 19 \mathrm{nl} / \mathrm{min} / \mathrm{M} 2$. In our study nasal exhaled NO concentration was significantly higher than oral exhaled NO concentration. Robbins et $\mathrm{al}^{14)}$, reported three different techniques of measuring exhaled NO (1) via the mouth directly into a NO chemiluminescence analyser (peak oral NO), (2) via the mouth into a collecting bag (mean oral NO), (3) via the nose into a collecting bag (mean nasal NO). Significant correlations were observed among the peak oral NO, mean oral NO and mean nasal NO.

In this study, we examined the influence of expiratory flow on exhaled oral and nasal NO using the bagtrap. We found that exhaled oral and nasal NO concentrations were also flow dependent. The possible importance of expiratory flow in the measurement of exhaled NO concentration has been reported by several investigators. Trolin et $\mathrm{al}^{15)}$, measured oral expired NO during exercise, and observed that the concentration of NO in expired air decreased during increasing intensity of the exercise. This may have been due to increased minute ventilation. Byrnes et $\mathrm{al}^{10)}$, reported peak concentrations of oral exhaled NO concentrations at four expiratory flow rates using the single breath method. Oral concentrations (SE) were 79.0 (15.5) ppb at $250 \mathrm{ml} / \mathrm{min}, 67.8$ (13.5) ppb at 500 $\mathrm{ml} / \mathrm{min}, 59.1(11.2) \mathrm{ppb}$ at $750 \mathrm{ml} / \mathrm{min}$ and 54.1 (10.7) $\mathrm{ppb}$ at $1100 \mathrm{ml} / \mathrm{min}$. There were strong linear relations between the NO concentrations and four flow levels $(r=0.85)$. Silkoff et $\mathrm{al}^{16)}$, presented evidence of a marked variation in NO plateau concentration using the single-breath method, which occurred as the expiratory flow varied from $4.2-1.550 \mathrm{ml} / \mathrm{sec}$. The NO plateau was $110.7(54.8) \mathrm{ppb}$ at a flow rate of $4.2 \mathrm{ml} / \mathrm{s}$, and $3.3(1.34) \mathrm{ppb}$ at a flow rate of $1550 \mathrm{ml} / \mathrm{sec}$. There was an almost 35 -fold increase in mean NO plateau as the flow fell from 1550 to $4.2 \mathrm{ml} / \mathrm{s}$.

In the direct nasal sampling method, sampling speed also influences nasal NO concentrations. Imada et $\mathrm{al}^{17)}$, measured nasal NO concentration in direct sampling from nasal cavity using bagtrap method. They reported hyperbolic relationship between nasal NO concentration and sampling flow rate. They suggest that nasal NO is excreted into the nasal cavity at a constant rate at rest. They reported nasal NO output is a product of $\mathrm{NO}$ concentration $\times$ flow rate. Khar-

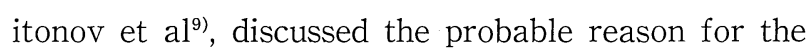
reduction in NO concentration with increased expiratory or sampling flow is that the same amount of NO will be dispersed in a different exhaled or sample volume.

Silkoff et al, measured nasal NO by five methods using rapid-response chemiluminescence analyzer. They compared nasal NO values and acceptability for subjects and technicians in five method. (1) Tidal nasal and oral breathing. (2) Fixed flow nasal and oral exhalation. (3) Nasal-oral aspiration. (4) Aspiration from one nares. (5) Nasal insuflation. They reported flow dependence of nasal NO using method 3. Nasal NO concentration showed a significant inverse linear relationship with flow. The method 2 had excellent general acceptability by both subjects and technicians. They concluded the fixed flow $(100 \mathrm{ml} / \mathrm{s})$ nasal and oral exhalation is to be recommend. In our study, technical procedure was similar to method 2 in Silkoff's study. In our procedure, fixed flow exhalation is the most important to measure exhaled NO concentration. We had the highest acceptability for subjects at a flow rate of $0.1 \mathrm{~L} / \mathrm{s}$ in oral and nasal exhalation.

Kharitonov et al, ${ }^{9)}$ reported that the measurement of exhaled NO is very useful for individual monitoring of respiratory inflammation. Thus, the clinical utility of exhaled NO also needs to be explored in longitudinal studies, with repeated measurements in the same patients and correlation with clinical parameters.

In the present study, the concentrations of oral and nasal exhaled NO showed widespread variability among individual subjects at different flow rates. Thus, our findings support the Kharitonov conclusion.

\section{Conclusions}

The measurement of exhaled NO must be performed in a standardized manner to enable comparison of the results among different studies. Exhaled oral and nasal NO concentrations using the bagtrap method were well correlated with the expiratory flow rate. An increase in expiratory flow rate resulted in a 
decreased concentration of NO.

The results of this study suggest that exhaled oral and nasal NO concentrations using bagtrap method were also flow dependent, and thus constant expiration $(0.1 \mathrm{~L} / \mathrm{s})$ is recommended.

\section{References}

1) Alving K, Weitzberg E, Lundberg JM : Increased amount of nitric oxide in exhaled air of athmatics. Eur Respir J 6 : 1368-1370, 1993.

2 ) Barnes PJ, Belvisi MG: Nitric oxide and lung disease. Thorax 48: 1034-1043, 1993.

3 ) Dillon WC, Hample V, Shultz PJ, et al: Origin of breath nitric oxide in human. Chest 110:930938, 1996.

4 ) Döttsch J, Demirakca S, Terback HG, et al : Airway nitric oxide in at hmatic children and patients with cystic fibrosis. Eur Respir J 9 : 2537-2540, 1996.

5 ) Ogoshi T, Miyazaki Y, Ishibashi M, et al: Influence of ambient nitric oxide on the exhaled NO test. Jpn J Rhinol 39: 359-364, 2000.

6 ) Gerlach H, Rossaint R, Pappert D, et al : Autoinhalation of nitric oxide after endogenous synthesis in nasopharynx. Lancet 343 : 518-519, 1994.

7 ) Lundberg JON, Szallsi F, Weitzberg E, et al : High nitric oxide production in human paranasal sinuses. Nature Med 11: 370-373, 1995.

8 ) Lundberg JON, Weizberg E, Lundberg JM, et al : Nitric oxide in exhaled air. Eur Respir J 9 : 2671-2680, 1996.

9 ) Kharitonov S, Alving K, Barnes PJ : Exhaled and nasal nitric oxide measurement: recommendations. Eur Respir J 10: 1683-1693, 1997.

10) Byrnes CA, Dinarevic S, Busst C, et al : Effect of mesurement conditions on measured levels of peak exhaled nitric oxide. Thorax 52:697-701,
1997.

11) Placentini G, Bondini A, Vino L, et al : Influence of environmental concentration of $\mathrm{NO}$ on the exhaled NO tests. Am J Respir Crit Care Med 158 : 1299-1301, 1998.

12) Borland C, Cox Y, Higenbottam T. Measuremet of exhaled nitric oxide in man. Thorax 48 : 1160-1162, 1993.

13) Kimberly B, Nejadnik B, Giraud GD, et al : Nasal contribution to exhaled nitric oxide at rest and during breathholding in humans. Am J Respir Crit Care Med 153 : 829-836, 1996.

14) Robbins RA, Floreani AA, Von Essen SG, et al : Measurement of exhaled nitric oxide by three different techniques. Am J Respir Crit Care Med 153 : 1631-1635, 1996.

15) Trolin G, Anden T, Hedenstierna G : Nitric oxide (NO) in expired air at rest during exercise. Acta Physiol Scand 15: 159-163, 1994.

16) Silkoff PE, McClean PA, Slutsky AS, et al: Marked fiow-dependence of nitric oxide using a new technique to exclude nasal nitric oxide. Am Respir Crit Care Med 155 : 260-267, 1997.

17) Imada $M$, Iwamoto J, Nonaka S, et al: Measurement of nitric oxide in human nasal airway. Eur Respir J 9 : 556-559, 1996.

18) Silkoff PE, Chatkin J, Qian w, et al: Nasal nitric oxide: A comparison of measurement techniques. Am J Rhinol 13 : 169-178, 1999.

（2001年10月 3 日受稿，2001年11月 2 日受理） 別刷請求先：Toshio Ogoshi, M.D.

Dept. of Otolaryngology

Toho Univ. Ohashi Hospital

2-17-6 Ohashi, Meguro-ku, Tokyo

153-8515, Japan

Tel : 03-3468-1251, Fax : 03-3468-3970 